\title{
Unity Power Factor Rectifier using Scalar Control Technique
}

\author{
A.G.Vishal Anand, Neeraj Gupta, V. Ramanarayanan
}

\begin{abstract}
The widely used Resistance Emulation technique for eliminating the problem of harmonic pollution of the Power Distribution system is based on the concept that the rectifier presents a pure resistive load to the ac system. In such a case, input voltage and current will have the same waveshape and will be in phase. Over the recent past, many methodologies based on the Resistance Emulation technique have been proposed in the literature. There has been a consistent attempt to introduce simplified control, higher efficiency and cost effectiveness in various emerging techniques. Scalar Control Method based Resistance Emulation technique, which is being discussed in this paper, is also an endeavor in the same direction. In this paper, the details of Sexalar Control theory, analysis, modeling, simulation and experimental results obtained by using this technique have been presented.
\end{abstract}

\section{INTRODUCTION}

Conventional power converters with diode capacitor rectifier front end have distorted input current with high harmonic content in the line currents. It is well known that these harmonic currents cause several problems such as voltage distortion, heating, and noises, reducing the capacity of the line to supply energy. Owing to this fact and the adoption of standards such as 1000-3-2 [1], there's a need for power supplies that draw current with low harmonic content \& also have power factor close to unity. So far, a variety of passive [2-4] and active PFC techniques have been proposed. While the passive PFC techniques may be the best choice at low power, cost sensitive applications, the active PFC techniques are used in majority of the applications owing to their superior performance.

The active PFC converters can be implemented either using the two-stage approach [5] or the single-stage approach. Unity power factor and high output voltage regulation are achieved in two-stage approach by the addition of a converter for input current shaping at the $\mathrm{AC}$ line side of the conventional switching power supplies as shown in Fig. 1. The price that is paid for meeting the objectives of sinusoidal input current \& output voltage regulation are

A. G. Vishal Anand is with the Department of Electrical Engg., Indian Institute of Science, Bangtlore-560012 ( vishal@ee iisc.ernet.in)

Neeraj Gupta is with the Department of Electrical Engg., Indian Institute of Science, Bangalore--5610012 ( neeraj@ee.iisc.ernet.in)

V. Ramanarayanan is with the Department of Electrical Engg, Indian Institute of Science, Bangalore-56001 2 ( vran@ee.iisc.ernet.in)
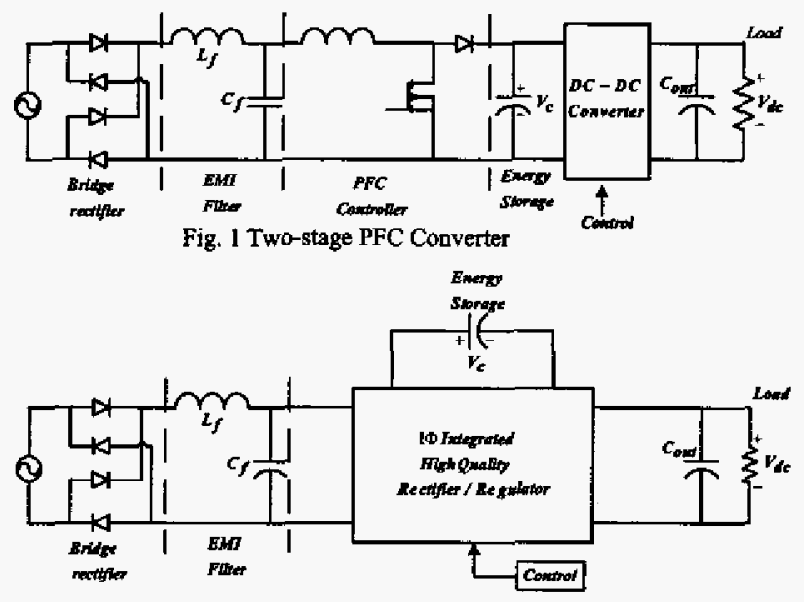

Fig. 2 Single-stage PFC Converter

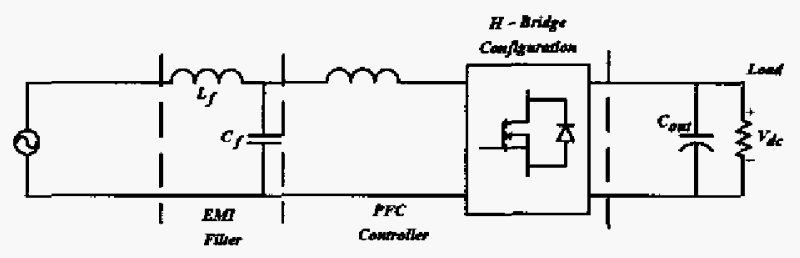

Fig. 3 Sealar Control based PFC Converter

- Requirement of two control loops

- Big storage capacitor

- Additional DC_DC converter

While the two-stage approach is a cost effective approach in high power applications, its cost-effectiveness is reduced in low power applications due to the additional $\mathrm{PFC}$ power stage and additional control circuitry. A number of active single stage PFC techniques [6-9] have been introduced in the recent years as a low cost alternative to this problem. It involves integration of the active PFC stage with the isolated DC-DC stage as shown in Fig. 2.

In this approach only one switch and hence only one controller is used to shape the input current and to regulate the output voltage. Here, the storage capacitor that's used for storing the difference between the instantaneous input power and constant output power is no longer loosely regulated at a constant value. It happens so because the controller is used to regulate the output voltage and not $V_{\mathrm{dc}}$. So the downside 
associated with this approach is that the size and the cost of electrolytic capacitor is much greater than that used in the two-stage approach. So the reduction in cost achieved by using single switch \& controller would be offset by employing a larger sized capacitor.

The single stage PFC converter, used for obtaining UPF at line side and tight voltage regulation, through scalar control technique is as shown in Fig. 3.In the new topology proposed, the front-end diode bridge rectifier circuit is dispensed with. Also the energy storage capacitor is removed because the unbalanced energy is now taken care of by output capacitor $C$ itself. Here the controller employed is DSP based which senses input current and output dc voltage for achieving the requisite control. The Scalar Control algorithm used in the DSP controller results in input sinusoidal current and loosely regulated dc voltage at the output if only input current is used as the sensing signal for DSP controller. While the same algorithm results in UPF at the line side and tight voltage regulation if both input current and output voltage are fed into the DSP controller. As voltage across the capacitor is regulated unlike a conventional single stage PFC converter, the size and cost of capacitor is reduced. In addition to this, there are other advantages accrued by using this topology.

1. Control algorithm is very simple to implement.

2. Input voltage need not be measured.

3. Control is based on carrier (constant switching frequency) and is simple to realize.

4. At the cost of one extra active device, number of passive devices is reduced.

5. Efficiency will be higher on account of the fact that only one device is in the series path of processed power.

6. The operation is always under CCM.

\section{SCALAR CONTROL THEORY}

Many UPF Rectifiers [10-12] proposed in recent times, have significant improvement over their predecessor circuits. These UPF Rectifiers have an uncontrolled rectification stage followed by a controlled boost/buck-boost topology. In Scalar Control technique, at the cost of increasing the number of controlled devices, the uncontrolled rectification stage can be totally removed. This method has simpler control algorithm and easier implementation to its credit than the existing techniques.

The boost rectifier configuration to which Scalar Control is applied is as shown in the Fig.4. On applying Volt-sec balance to the line inductance,

$$
\mathrm{V}_{\mathrm{a}}=\frac{\mathrm{V}_{\mathrm{dc}}(1-2 \mathrm{~d})}{2}
$$

where, the terms are as mentioned in Fig. 4.

For obtaining resistance emulation characteristics, the input voltage \& input current are related by the relation,

$$
\mathrm{V}_{\mathrm{a}}=\mathrm{I}_{\mathrm{a}} \mathbf{R}_{\mathbf{c}}
$$

where $R_{\mathrm{e}}$ is the emulated resistance.

From (1) \& (2), the Control Law obtained is,

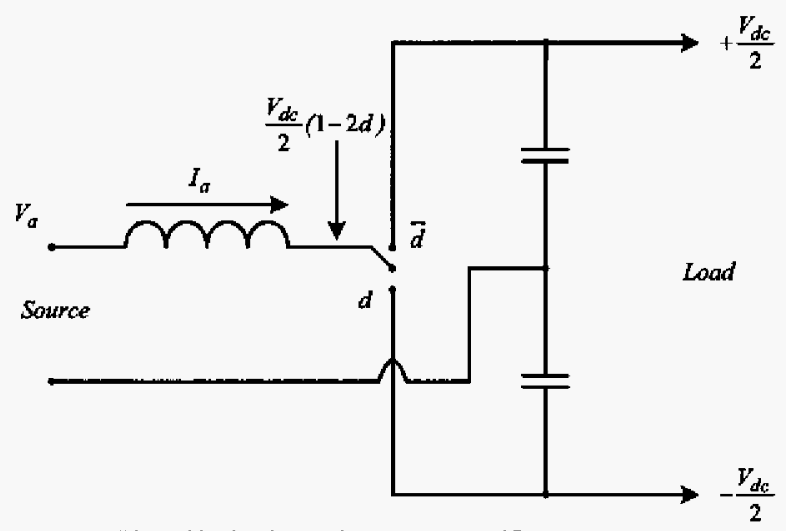

Fig- 4 Single-phase Direct Boost Rectifier

$$
\mathrm{d}=\frac{1}{2}-\frac{\mathrm{I}_{\mathrm{a}} \mathrm{R}_{\mathrm{e}}}{\mathrm{V}_{\mathrm{dc}}}
$$

By varying the duty ratio in accordance with the above Control Law, UPF operation can be achieved. Here, only the input current \& DC bus voltage need to be sensed for achieving the control. The Control Law is very simple to implement as is evident from (3). The control scheme is also independent of the input voltage.

For single phase Scalar Control implementation, the advantages might not be too marked, since four controlled devices are used. But when the same technique is extended to three-phase system, the advantages accrued are quite distinctive, for the control is decoupled in nature and does not require transformations to the stationary frame of reference as is used for a conventional three-phase PFC converter. This configuration could also be controlled to obtain bi-directional power flow, which might not be possible with a three-phase diode bridge on the $\mathrm{AC}$ side.

However, the focus of the work reported in this paper is on single-phase Direct Boost rectifier. The same idea could also in principle be extended to three-phase operation.

\section{SYSTEM MODELING}

The Block diagram of the scalar controlled PFC controllet is shown in Fig. 5. It can be seen that there are two cascaded control loops in the entire scheme. The outer voltage loop provides a current reference $I_{\text {ref }}$ to the inner current loop. Under steady state, the current reference is a DC quantity. The input current is normalized with respect to the reference current, $I_{\text {ref }}$ to generate the Normalized current reference. The Pulse width modulator shown in Fig. 5 has a standard sawtooth ramp generator. The switching instants are produced by comparison of the ramp with the Normalized current reference as shown in Fig. 6. On applying Volt-sec balance on the line inductor, 


$$
V_{d e}=\frac{V_{a}}{(1-2 d)}
$$

Where

$\mathrm{V}_{\mathrm{a}}$ is the applied $\mathrm{AC}$ voltage

$V_{d c}$ is the DC bus voltage

$\mathrm{d}$ is the duty ratio of the switch

From (4) \& (2) the Control Law for the Scalar Control based PFC controller is,

$$
\mathrm{d}=\frac{1}{2}\left[1-\frac{\mathrm{I}_{\mathrm{a}} \mathrm{R}_{\mathrm{e}}}{\mathrm{V}_{\mathrm{dc}}}\right]=\frac{1}{2}\left[1-\frac{\mathrm{I}_{\mathrm{a}}}{\mathrm{I}_{\mathrm{ref}}}\right]
$$

Where

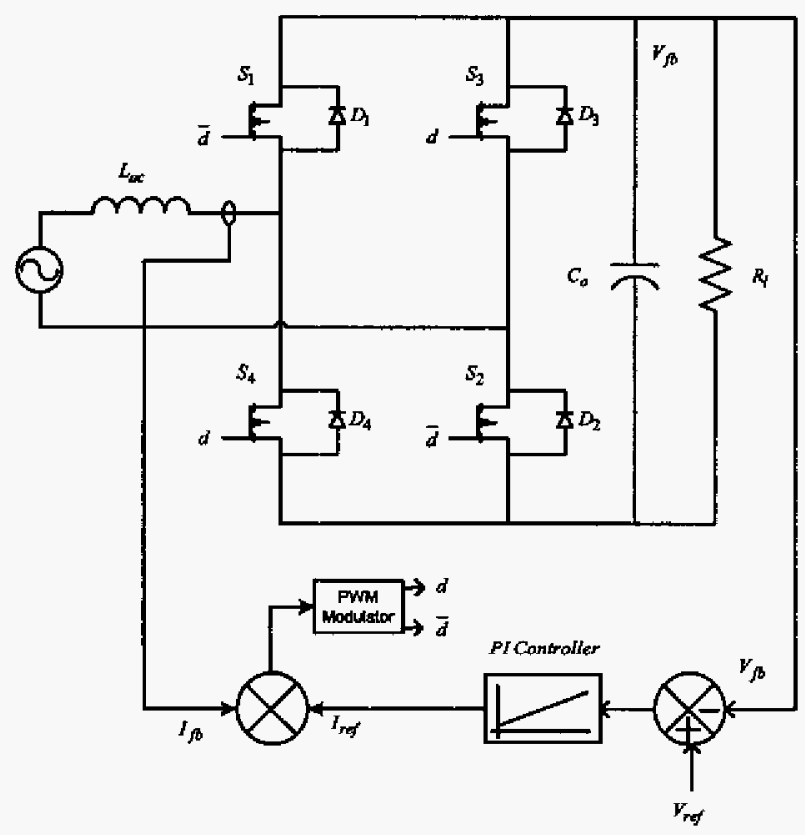

Fig. 5 Block Diagram of Scalar Control PFC Converter

$$
I_{\text {ref }}=\frac{V_{d c}}{R_{e}}
$$

and is known as the current reference.

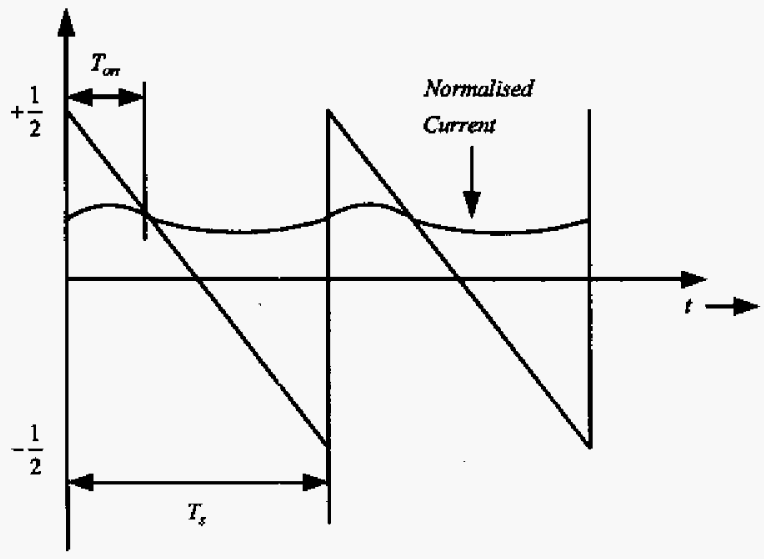

Fig. 6 Duty ratio command generation

\section{STEADY STATE STABILITY}

The steady state stability analysis of Scalar Controlled Boost converter is carried out here. Like current mode controlled converters, it may also exhibit steady state stability problem under certain operating conditions due to the presence of local feedback in its control structure [13]. The objective of the analysis here is to quantify the steady state stability condition in terms of circuit parameters and the switching frequency of the converter.

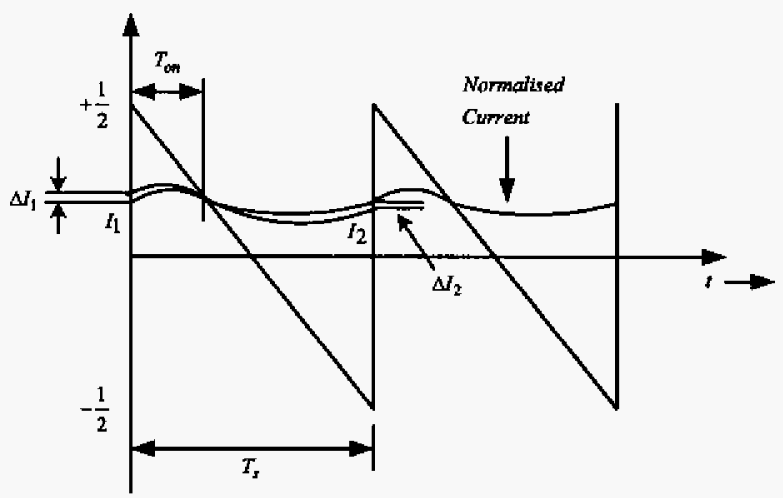

Fig.7 Perturbation analysis to evaluate steady state stability condition

Let $I_{1} \& \quad I_{2}$ be the currents at the start and end of a switching cycle respectively as shown in Fig. 7 . Let $\Delta \mathrm{I}_{1}$ be a small perturbation introduced in $I_{1}$ which produces a change $\Delta \mathrm{I}_{2}$ in current $\mathrm{I}_{2}$. From (5),

$$
\mathrm{d}=\frac{1}{2}\left[1-\frac{\mathrm{I}_{\mathrm{a}}}{\mathrm{I}_{\mathrm{ref}}}\right]
$$

Differentiating both sides with respect to line current $I_{1}$

$$
\frac{\Delta \mathrm{d}}{\Delta \mathrm{I}_{1}}=-\frac{1}{2 * \mathrm{I}_{\text {ref }}}
$$

From the steady state model of the boost converter, we get

$$
\mathrm{L} \frac{\mathrm{dI}}{\mathrm{dt}}=\mathrm{V}_{\mathrm{a}}-\mathrm{V}_{\mathrm{dc}}(1-2 \mathrm{~d})
$$

Differentiating both sides with respect to $d$, we get

$$
\frac{\Delta \mathrm{I}_{2}}{\Delta \mathrm{d}}=\frac{\mathrm{V}_{\mathrm{dc}}\left(2 * \mathrm{~T}_{\mathrm{s}}\right)}{\mathrm{L}}
$$

Where,

$\mathrm{T}_{\mathrm{s}}$ is the switching frequency

$\mathrm{L}$ is the Line Inductance. Multiplying (8) \& (10), we get

$$
\left|\frac{\Delta \mathrm{I}_{2}}{\Delta \mathrm{I}_{1}}\right|=\frac{\mathrm{V}_{\mathrm{dc}} \mathrm{T}_{\mathrm{s}}}{\mathrm{LI}_{\mathrm{ref}}}
$$

A Converter is said to be stable in steady state if all perturbations die down in subsequent cycles, which implies that the expression in (11) should be less than 1 . Therefore the 
condition for stability of the scalar control method is given as,

$$
\left|\frac{\Delta \mathrm{I}_{2}}{\Delta \mathrm{I}_{1}}\right|=\frac{\mathrm{V}_{\mathrm{dc}} \mathrm{T}_{\mathrm{s}}}{\mathrm{LI}_{\mathrm{ref}}} \leq 1
$$

\section{SMALL SIGNAL ANALYSIS}

A linear, low frequency, small signal model of Boost converter is developed here. It may be noted that, in a dc-dc converter, when it is operating under steady state, the input power is equal to the output power in every switching period $\mathrm{T}_{\mathrm{s}}$ of the converter. However the same is not true for singlephase resistor emulator rectifiers. The input voltage $V_{a}$ varies from 0 to $V_{m}$ in a line cycle and under steady state condition, the input current $I_{a}$ is proportional to the input voltage. The instantaneous input power is, therefore $v_{g} i_{g}=\frac{v_{g}^{2}}{R_{e}}$ which is not constant within an input cycle $T=\frac{1}{2 f}$ whereas the instantaneous output power $\frac{V_{d c}^{2}}{R}$ is constant. So, unlike dc-dc converter, the power balance condition between input and output cannot be satisfied at every switching period of the resistor emulator rectifiers. However, it may be noted that, the instantaneous input power is equal to the output power only at the period in which the input voltage is $\frac{V_{m}}{\sqrt{2}}$. Therefore this switching period is chosen as the equivalent nominal opetating point that represents the entire line cycle for the derivation of the small signal model. The control structure of the small signal linear model of the Boost rectifier, switched by input current shaping modulator, governed by Scalar Control Law, is as shown in Fig. 8

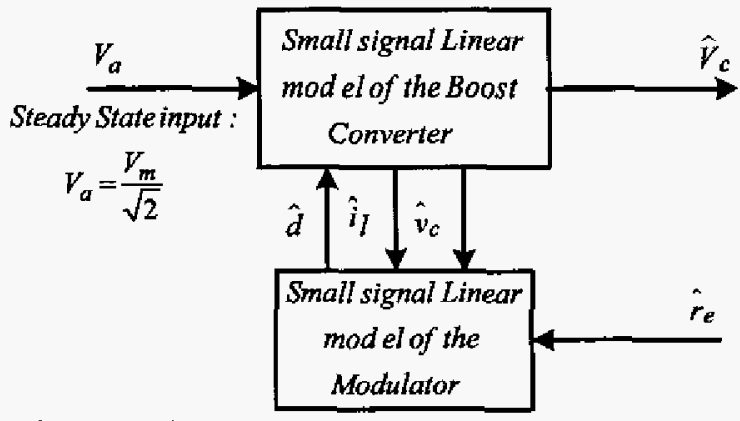

Fig. 8 Control structure of Low frequency stall signal Boost rectifier

Here the control gain transfer function is derived in two steps [14][15]. First, the low frequency small signal model of the Boost Converter is obtained in the standard form in terms of duty ratio perturbation $\hat{d}$ as the control input. Subsequently the small signal model of the modulator is derived to replace $\hat{d}$ term in the converter model by the perturbations in $\hat{r}_{e}$ and other state variables $\hat{\mathrm{i}}_{1} \& \hat{\mathrm{v}}_{\mathrm{c}}$

The state variable description of the converter is given by (13)

$\left[\begin{array}{c}\frac{\mathrm{di}_{1}}{\mathrm{dt}} \\ \frac{\mathrm{dv_{ \textrm {c } }}}{\mathrm{dt}}\end{array}\right]=\left[\begin{array}{cc}0 & \frac{2 \mathrm{D}-1}{\mathrm{~L}} \\ \frac{1-2 \mathrm{D}}{\mathrm{C}} & -\frac{1}{\mathrm{RC}}\end{array}\right]\left[\begin{array}{l}\mathbf{i}_{1} \\ \mathrm{v}_{\mathrm{c}}\end{array}\right]+\left[\begin{array}{c}\frac{1}{\mathrm{~L}} \\ 0\end{array}\right] \mathrm{V}_{\mathrm{a}}$

where, $\mathrm{D}$ is the duty ratio of the converter about the operating point \& $V_{a}$ is the input voltage to the converter. The linear small signal model of the Boost converter is obtained by perturbing the state variables and the duty ratio input. The generalized small signal model equation is given as,

$$
\frac{d \vec{x}}{d t}=A \hat{x}+B \hat{v}_{a}+f \hat{d}
$$

Where, A, B \& f represent system matrices \& $\hat{x}, \hat{v}_{\mathfrak{a}}, \hat{\mathrm{d}}$ are the perturbed variables. Equation (5) representing the steady state relationship between the system variables \& the duty ratio, d when perturbed, will yield the relationship between the small signal $\hat{d} \&$ the other system variables as given in (15)

$$
\hat{\mathrm{d}}=\left(\frac{\mathrm{I}_{1} \mathrm{R}_{\mathrm{e}}}{2 \mathrm{~V}_{\mathrm{c}}^{2}}\right) \hat{\mathrm{v}}_{\mathrm{c}}-\left(\frac{\mathrm{R}_{\mathrm{c}}}{2 \mathrm{~V}_{\mathrm{c}}}\right) \hat{\mathrm{i}}_{1}-\left(\frac{\mathrm{I}_{1}}{2 \mathrm{~V}_{\mathrm{c}}}\right) \hat{\mathbf{r}}_{\mathrm{e}}
$$

Where, $\hat{I}_{e}$ is the perturbed value of the emulated resistance, $\mathbf{R}_{\mathrm{e}}$.

Substituting (15) in (14) yields,

$$
\left[\begin{array}{c}
\frac{d \hat{i}_{l}}{d t} \\
\frac{d \hat{v}_{c}}{d t}
\end{array}\right]=\left[\begin{array}{cc}
-\frac{R_{e}}{L} & 0 \\
\frac{2(1-2 D)}{C} & \frac{-2}{R C}
\end{array}\right]\left[\begin{array}{l}
\hat{\mathrm{i}}_{1} \\
\hat{v}_{c}
\end{array}\right]+\left[\begin{array}{c}
\frac{1}{L} \\
0
\end{array}\right]{\hat{V_{a}}}+\left[\begin{array}{c}
-\frac{I_{l}}{L} \\
\frac{I_{l}^{2}}{C V_{c}}
\end{array}\right] \hat{\mathrm{r}}_{e}
$$

It is observed from the system matrix, 'A' of (16) that the product of off-diagonal terms is zero which implies that the system has real poles. Moreover, the term $-\frac{\mathbf{R}_{\mathbf{e}}}{\mathrm{L}}$ in system matrix ' $A$ ' introduces additional damping to the system response, making the system stable.

From (16), the transfer function of the converter can be equated as,

$$
\frac{\hat{v}_{\mathrm{c}}(s)}{\hat{\mathrm{i}}_{1}(\mathrm{~s})}=\frac{\mathrm{R}_{\mathrm{e}}}{(1-2 \mathrm{D})} \frac{\left(1-\mathrm{s} \frac{\mathrm{L}}{\mathrm{R}_{\mathrm{e}}}\right)}{\left(1+\mathrm{s} \frac{\mathrm{RC}}{2}\right)}
$$

The Bode plot representation of (17) is shown in Fig. 9. For a closed loop control system to be stable, it's required that the loop gain crosses over $0 \mathrm{~dB}$ (Unity Gain) with a single slope ( $-20 \mathrm{~dB} /$ decade). For a given system, transfer function $|G|$ the design of the closed loop compensator $|H|$ should be such that the loop gain $|T|(|G||H|)$ satisfies the above requirement. As per the system transfer function given in (17) 
the bode plot of the Compensator (PI controller) shown in Fig. 10 satisfies the requisite condition of single slope $0 \mathrm{~dB}$ crossover.

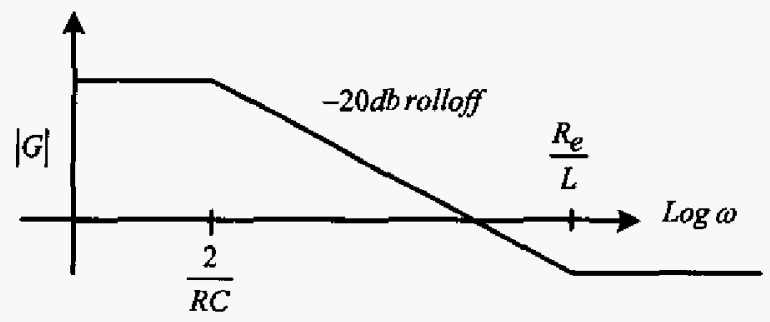

Fig. 9 Rode plot of system transfer function

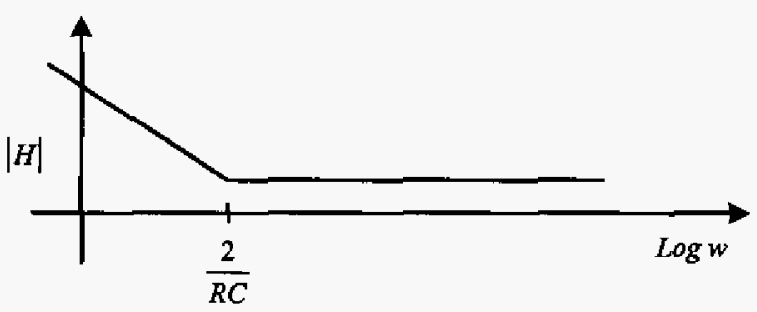

Fig. 10 B.ode plot of Compensator

\section{SIMULATION \& EXPERIMENTAL RESULTS}

The Scalar Controlled UPF rectifier is simulated in Orcad Pspice. The simulation results obtained, as shown in Fig. 11 are taken with an input voltage of $230 \mathrm{~V}$ (pk) and load resistance of $250 \Omega$. The Line inductance is kept small at 3 $\mathrm{mH}$ in order to have low voltage drop actoss it at full load. The switching frequency is chosen to be $10 \mathrm{kHz}$. The DC bus voltage is maintained constant at $360 \mathrm{~V}$.

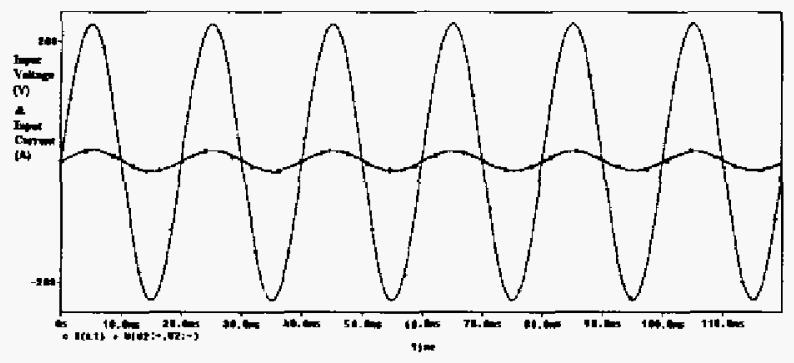

Fig. 11 (a) Input Voltage and Input Current in phase

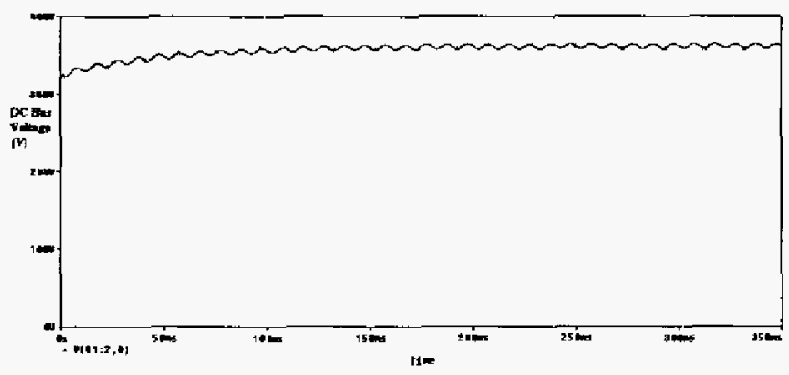

Fig. 11 (b) DC Bus Voltage regulated at $360 \mathrm{~V}$
The Control algorithm is tested for experimental verification on a $1 \mathrm{~kW}$ single-phase Boost rectifier unit. The $\mathrm{AC}$ line input is $138 \mathrm{~V}$ (rms) and the $\mathrm{DC}$ Bus voltage of the rectifier is regulated at $400 \mathrm{~V}$. The measured value of boost inductance is $11 \mathrm{mH}$. The switching frequency of the IGBT based (IPM Module) converter is chosen to be $10 \mathrm{kHz}$. The load resistance is fixed at $250 \Omega$.

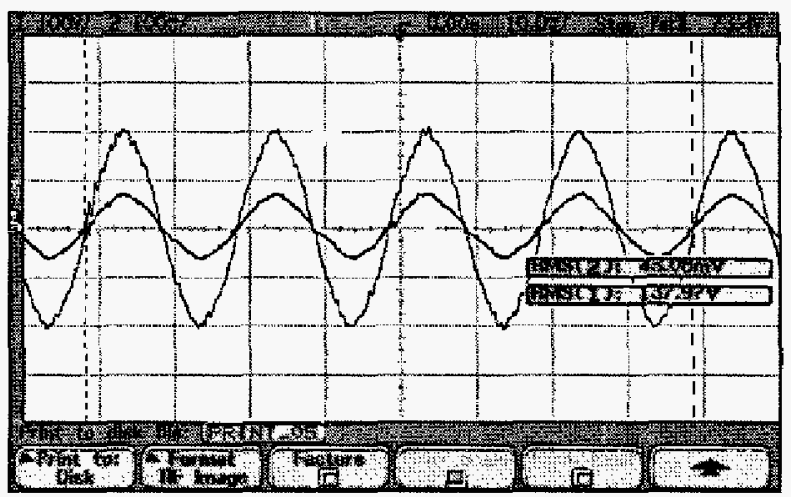

Fig. 12 (a) Ch1: Input Voltage ; Ch2: Input Current Voltage scale : $100 \mathrm{~V} /$ div. Current Scale : $10 \mathrm{mV} / \mathrm{A}$

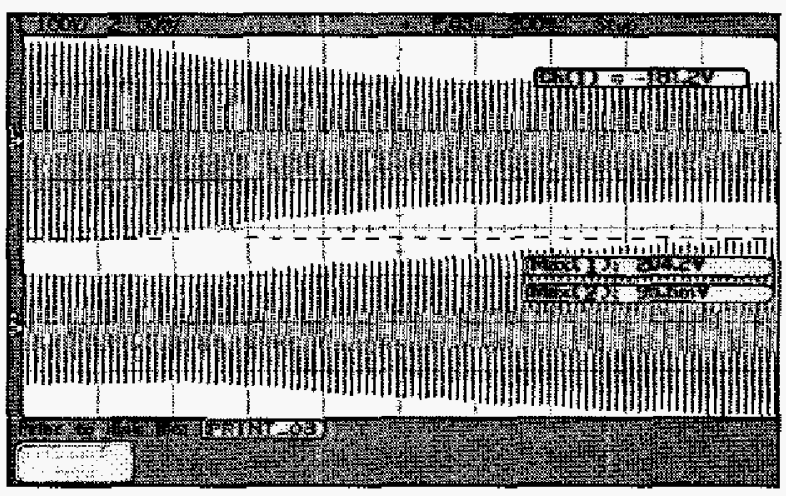

Fig. 12 (b) Ch1: Input Voltage ; Ch2: Input Current Voltage scale : $100 \mathrm{~V} / \mathrm{div}$. Current Scale : $10 \mathrm{mV} / \mathrm{A}$

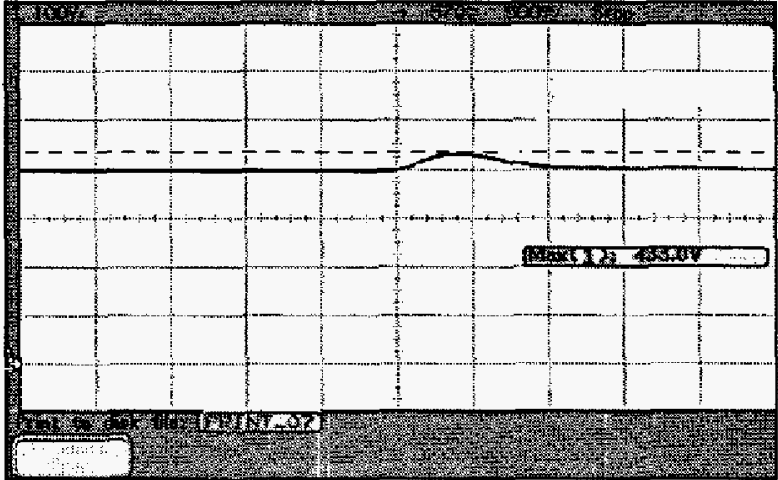

Fig. 12 (c) Chl: DC Bus Voltage Voltage scale : $100 \mathrm{~V} /$ div.

Fig. 12(a) shows UPF operation at the line side. Under constant load conditions, Fig. 12(b) shows an increase in the 
input current with the decrease in line voltage. Tight regulation of the $\mathrm{DC}$ bus voltage under the same condition is evident from Fig. 12(c). The THD of the input current waveform calculated from the FFT shown in Fig. 12(d) is found to be $12 \%$, which indicates a very high input power factor.

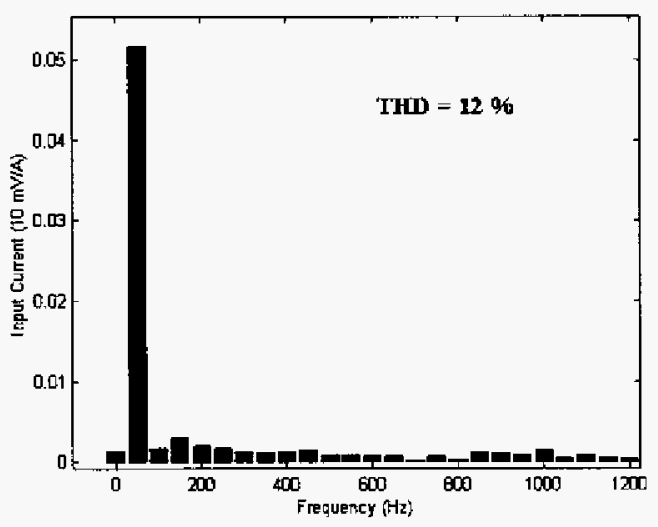

Fig. 12 (d) FFT of Input Current

\section{CONCLUSION}

In this paper, a novel active power factor correction technique named Scalar control is proposed and analyzed. With the proposed method, the power factor of the singlephase front-end converter is made unity without sensing the input voltage. The control is extremely simplified \& the same control technique could be extended to a three-phase system. The conditions for steady-state stability \& the small-signal model are derived. The proposed method has the disadvantage of instability under certain conditions because of the nature of the control. The results obtained from the simulation of the converter are also verified experimentally.

\section{REFERENCES}

[1] IEC 1000/3/2 International Standard, "Limits for harmonic current emissions (equipment input current $<16$ A per phase)", 1995.

[2] R. Redl, “An Economical Single Phase Power-Factor Corrected Rectifer: Topology, Operation, Extensions, and design for compliance", IEEE Applied Power Electronics Conference (APEC),1998.

[3] A.R Prasad, P.D. Ziogas, S. Manias, "A Novel Passive Waveshaping Method for Single Phase Diode Rectifiers", IEEE Transactions on Industrial Electronics,December 1990.

[4] E. Maset et al, "Improved Passive Solutions to meet IEC 1000-3-2 Regulation in low cost Power Supplies",International Telecommunications and Energy Conference (INTELEC) 1996.

[5] L.H Dixon, Jr., "High power factor pre-regulators for off-line power supplies,"Unitrode Switching Regulator Power Supply Design Seminar Manual, Paper 12, SEM$700,1990$.
[6] M.Madigan, R. Erikson, E. Ismail, "Integrated highquality rectifier-regulators," IEEE Power Electronics Specialists Conf.(PESC) Record, jun. 1992, pp. 1043 1051.

[7] S. Teramoto, M.Sekine, R. Saito, "High power factor AC/DC converter," U.S. Patent \#5,301,095, Apr.5, 1994.

[8] F.S. Tsai, et al, "Low cost AC-to-DC converter having input current with reduced harmonics," U.S. Patent \# $5,652,700$, July, $29,1997$.

[9] P. Vinciarelli, "Optimal resetting of the transformer's core in single-ended forward converters," U.S. Patent \# 4,441,146, April 1984.

[10] J.P. Gegner, C.Q. Lee, "Linear Peak Mode Control: A simple Active Power Factor Correction Control Technique for CCM," IEEE Power Electronics Specialisis Conf.(PESC) Record, june 1996, pp. 196-202.

[11] D. Maksimovic, Y. Jang, R.Erickson "Nonlinear-Carrier Control for High Power Factor Boost Rectifiers," APEC, 1995, pp.635-641.

[12] W. Tang, Y. Jiang, G. C. Hua, F. C. Lee, "Power Factor Correction with Flyback Converter employing Charge Control," IEEE APEC 1993, pp.293-298.

[13] S. Hsu, A. Brown, L Rensink, R. D. Middlebrook, "Modelling and Analysis of switching DC-to-DC Converters in Constant Frequency Current Programmed Mode," PESC, june 1979.

[14] F. Dong Tan , R. D. Middlebrook, "A Unified Model of Current Programmed Converters," IEEE Transactions on Power Electronics, Vol. 10, No. 4, pp.397-408, july 1995.

[15] R. D. Middlebrook, "`Topics in Multiple Loop Regulators and Current Mode Programming," IEEE Transactions on Power Electronics, Vol. PE-2, No. 2, pp.109-124, april 1987.

[16] R.W. Erickson, D. Maksimovic, "Fundamentals of Power Electronics : Second Edition, Chapter 16: Power and harmonics in nonsinusoidal systems," Publisher: Kluwer Academic Publishers, ISBN 0-7923-7270-0. 